\title{
POLÍTICAS FISCAIS COMO FOMENTO AO DESENVOLVIMENTO DE STARTUPS NO BRASIL: INCENTIVO À ECONOMIA NACIONAL
}

\section{Stéfani Clara da Silva Bezerra* Carlos César Sousa Cintra**}

\begin{abstract}
Resumo: A Quarta Revolução Industrial ou Indústria 4.0 baseia-se na fusão da tecnologia com os domínios físicos, digitais e biológicos. O Brasil, nesse contexto, ainda vive entre a segunda e a terceira revolução industrial. Para se alcançar esta nova etapa, é necessária uma mudança de abordagem quanto ao setor de empreendedorismo. O governo precisa apoiar financeiramente essas iniciativas privadas, em especial as startups, e apresentar um ambiente fiscal favorável. As startups vêm se destacando na formação do Produto Interno Bruto, apresentando-se como importante vetor de crescimento econômico, daí a relevância de incentivá-las e propiciar um ambiente fiscal favorável ao seu desenvolvimento.
\end{abstract}

Palavras-chave: Políticas Fiscais. Startup. Benefício Fiscal.Indústria 4.0. Nova Revolução Industrial.

\section{FISCAL POLICIES AS A PROMOTION TO THE DEVELOPMENT OF STARTUPS IN BRAZIL: INCENTIVE TO THE NATIONAL ECONOMY}

\begin{abstract}
The Fourth Industrial Revolution is based on the fusion of technology with physical, digital and biological domains. Brazil, in this context, still lives between the second and third industrial revolutions. In order to achieve this new stage, a change of approach regarding the entrepreneurship sector is necessary. The government needs to financially support these private initiatives, especially startups, and present a favorable tax environment. Startups have been prominent in the formation of the Gross Domestic Product, presenting itself as an important vector of economic growth, hence the importance of encouraging them and providing a favorable tax environment for their development.
\end{abstract}

Keywords: Fiscal Policies. Startup. Tax Benefit. Industry 4.0. New Industrial Revolution.

\section{INTRODUÇÃO}

Com o avanço da tecnologia e, consequentemente, o advento de uma nova revolução industrial, mais conhecida como Indústria 4.0, tem-se mostrado crescente o número de empreendimentos virtuais no cenário econômico do país. Apesar da criação de "negócios

\footnotetext{
* Mestranda em Direito e Desenvolvimento pelo Centro Universitário Christus (UNICHRISTUS). Especialista em Direito Processual Civil pela Faculdade Tecnológica de Palmas (FTP). Graduada em Direito pela Universidade de Fortaleza (UNIFOR). Advogada. E-mail: stefani.scb@gmail.com. ORCID ID: https://orcid.org/0000-0001-6789-318X

** Advogado. Doutor em Direito pela Pontifícia Universidade Católica de São Paulo. Professor do Programa de Pós-Graduação da Universidade Federal do Ceará e do Centro Universitário Christus (UNICHRISTUS). E-mail: cccintra@ gmail.com. ORCID: https://orcid.org/0000-0002-8287-4697.
}

Revista de Direito Tributário e Financeiro | e-ISSN: 2526-0138 | Porto Alegre | v. 4 | n. 2 | p. 103 - 121 | Jul/Dez. 2018 
digitais" apresentar-se, num primeiro momento, como uma promessa inovadora e com custos baixos, quando comparadas à fundação de grandes empresas, o cenário político-tributário não tem se mostrado receptível às startups.

A burocracia, os altos custos e a incidência de diversos tributos apresentam-se como obstáculos quando da criação e manutenção destas empresas digitais. Verifica-se, portanto, uma carência de incentivo financeiro por parte do Poder Público, assim como falta de divulgação de regulamentação específica que beneficiem as mesmas.

No Brasil, o apoio a essas empresas pode ser observado pelo Sebrae e pela Finep que tem como missão apoiar pequenos empreendimentos, a fim de se tornarem competitivos no mercado e autossustentáveis. Enquanto que, no âmbito legislativo, apresentam-se a Lei de Inovação (Lei n. 10.973/2004, alterada pela Lei n. 13.243/2016), a Lei do Bem (Lei n. 11.196/05) e a Lei do Investidor Anjo (Lei Complementar n. 155/2016). Dentre estas práticas de incentivo normativo, cumpre salientar a alteração da Lei Complementar n. 116/2003 pela Lei Complementar n. 157/2016 acerca da cobrança de ISS (Imposto Sobre Serviço) que implicou em mudanças positivas e negativas quanto à tributação das startups.

A presença das grandes corporações nesse ambiente de inovações tecnológicas tem se mostrado de suma relevância, haja vista o financiamento e investimento praticado por estas empresas em prol dos pequenos negócios, participando, ainda que indiretamente, da formação do Produto Interno Bruto - PIB.

O Brasil se encontra numa fase de transição do modelo de indústria 2.0 para 3.0, enquanto diversos países já estão vivenciando a nova revolução industrial, também conhecida como Indústria 4.0, caracterizada por um conjunto de tecnologias que permitem a fusão do mundo físico, digital e biológico.

Com efeito, para que o país alavanque seu crescimento, traduzido pelo PIB na presente abordagem, e consiga acompanhar esta nova fase econômica, exige-se que sejam implementadas políticas de incentivo e fomento que auxiliem o desenvolvimento destas empresas de tecnologia.

Dentre estas práticas tributárias, destaca-se a concessão de subsídio no formato de benefício fiscal tanto para criar como para auxiliar o desenvolvimento das startups nacionais, de modo que estas, em contrapartida, poderiam criar um ambiente favorável aos programas sociais de fomento à pesquisa e tecnologia, assim como a Finep (Financiadora de Estudos e Projetos). 
A presente pesquisa será desenvolvida através de uma abordagem qualitativa, utilizando o método indutivo, o que permitirá uma melhor análise do objeto em estudo, procurando aprofundar a compreensão e discussão sobre a adoção de uma política fiscal mais adequada, a fim de proporcionar um ambiente favorávelà criação e ao desenvolvimento de startups nacionais (MACEDO, 1995).

\section{BRASIL NO CONTEXTO DA NOVA REVOLUÇÃO INDUSTRIAL}

A primeira Revolução Industrial remonta ao século XIX (1760 a 1850). Nesse período, limitava-se praticamente à Inglaterra que, naquele momento, constituía-se na "oficina do mundo" (ARRUDA, 1982). Nesse primeiro momento, preponderou a produção de bens de consumo, construção de ferrovias, invenção da máquina a vapor, dando, assim, início à produção mecânica (SCHWAB, 2016, p. 15).

Dos anos de 1850 a 1900, final do século XIX e início do XX, a Revolução Industrial foi bastante difundida pela Europa, América e Ásia. Com o advento da eletricidade e da linha de montagem, foi possível a produção em massa. Esta segunda fase também é marcada pelo surgimento de novas formas de energia, tais como hidrelétricas, combustíveis derivados do petróleo, o que levou à invenção do motor de explosão e, consequentemente, à revolução nos transportes marítimos e terrestres (ARRUDA, 1982).

A terceira Revolução Industrial começou na década de 1960, também conhecida como revolução digital ou do computador, haja vista ter sido estimulada pela criação de semicondutores, da computação em mainframe, da computação pessoal e da internet (SCHWAB, 2016). Ressalte-se, ainda, o surgimento de grandes conglomerados industriais e das multinacionais, automação da produção, possibilitando, assim, a produção em série e em larga escala. Nessa fase, verificou-se, também, um avanço na indústria química e eletrônica, da engenharia genética e da cibernética (ARRUDA, 1982).

A quarta Revolução Industrial teve início na virada do século, baseando-se, para tanto, na era digital. Esta fase se caracteriza por uma internet onipresente no cotidiano das pessoas, por sensores mais compactos e poderosos que, por sua vez, se tornaram mais acessíveis, bem como pela inteligência artificial e aprendizagem automática. Todavia as inovações não se limitam ao sistema de máquinas inteligentes em conexão. Parte-se para novas descobertas simultâneas em áreas que tratam desde o sequenciamento genético até a 
nanotecnologia e aquelas que cuidam de energias renováveis e computação quântica. $\mathrm{O}$ diferencial desta revolução é a fusão da tecnologia com os domínios físicos, digitais e biológicos (SCHWAB, 2016).

Esta nova etapa industrial tem sido divulgada sob o nome de Indústria 4.0, podendo ser definida, segundo a chanceler Angela Merkel (ROMANO, 2017, online) da Alemanha, país de onde surgiu o termo, como "a transformação completa de toda a esfera da produção industrial através da fusão da tecnologia digital e da internet com a indústria convencional”. Apesar de possuir origem alemã, o termo Indústria 4.0 já se propagou por diversos países, tendo os governos destes tomado diversas iniciativas para seguir essa nova tendência mundial.

Dentre estes países, segundo especialistas (FIRJAN, 2016, p. 16), boa parte da indústria brasileira encontra-se em transição do que poderia se denominar indústria 2.0 (constituída por linhas de montagem e energia elétrica) para indústria 3.0 (caracterizada pela automação, robótica e programação). O grande desafio a ser enfrentado pelo Brasil, segundo relatório sobre tendências tecnológicas, produzido pela Diretoria de Inovação do SENAI-Rio, é:

\begin{abstract}
Obter políticas estratégicas inteligentes, incentivos e fomentos por parte do governo; reunir empresários e gestores da indústria com visão, arrojo e postura proativa; dispor de desenvolvimento tecnológico e formação de profissionais altamente qualificados por parte das instituições acadêmicas e de pesquisa, preferencialmente em grande proximidade com a indústria (FIRJAN, 2016, p. 17).
\end{abstract}

A agenda da Indústria 4.0, formulada pelo Governo Federal com diretrizes a serem seguidas para propiciar o desenvolvimento do país e sua consequente inserção na Quarta Revolução Industrial, é composta por quatro premissas:

1) Fomentar inciativas que facilitem e habilitem o investimento privado, haja vista a nova realidade fiscal do país.

2) Propor agenda centrada no industrial/empresário, conectando instrumentos de apoio existentes, permitindo uma maior racionalização e uso efetivo, facilitando o acesso dos demandantes, levando o maior volume possível de recursos para a "ponta".

3) Testar, avaliar, debater e construir consensos por meio da validação de projetospiloto, medidas experimentais, operando com neutralidade tecnológica.

4) Equilibrar medidas de apoio para pequenas e médias empresas com grandes companhias (BRASIL, 2017, online).

Essas medidas apresentadas possuem como finalidade primordial auxiliar os empresários brasileiros nesta jornada rumo à transformação digital e ao futuro da produção 
manufatureira (BRASIL, 2017). Apesar do cenário industrial nacional se apresentar ainda inserido tanto na fase 2.0 como 3.0 da indústria, a mudança de postura do Brasil com relação a esse setor pode desencadear uma transição mais breve e vantajosa, haja vista a economia de tempo quanto ao retorno de recursos financeiros a serem empregados pelo governo.

\section{AS STARTUPS NO CONTEXTO BRASILEIRO}

Dentre as tecnologias trazidas pela Indústria 4.0, encontra-se o formato startup que, segundo definição dada pelo especialista Yuri Gitahy, em entrevista à Revista Exame (MOREIRA, 2016, online), "significa um grupo de pessoas trabalhando com uma ideia diferente que, aparentemente, poderia fazer dinheiro". O Sebrae (2018, online) apresenta uma definição mais atual e ampla: "startup é um grupo de pessoas à procura de um modelo de negócios repetível e escalável, trabalhando em condições de extrema incerteza”.

Tipo bem comum são aquelas que desenvolvem aplicativos, dada a praticidade e economia de tempo que estes proporcionam aos consumidores, bem como em razão da facilidade com a qual são produzidos e testados (ALVES, 2013).

No Brasil, o incentivo ao desenvolvimento de startups é pouco expressivo. Esse papel acaba sendo desempenhado, em grande parte, pelo Sebrae, uma entidade privada de interesse público que tem como finalidade apoiar pequenas empresas e torna-las competitivas e autossustentáveis (FIRJAN, 2016).

Por outro lado, tem-se a figura da Finep Startup, um programa que "tem por objetivo apoiar a inovação em empresas nascentes intensivas em conhecimento através do aporte de recursos financeiros para execução de seus planos de crescimento." (EMPRESA BRASILEIRA DE INOVAÇÃO E PESQUISA, 2018, online).

Segundo relatório da Brasscom - Associação Brasileira das Empresas de Tecnologia da Informação e Comunicação (2017, online):

No Brasil foram criadas iniciativas públicas e privadas que buscam estimular o crescimento de Startups. De acordo com a Associação Brasileira de Startups existem pelo menos 10.000 empresas deste tipo no país. Iniciativas como a criação do programa Startup Brasil, do MCTI - Ministério da Ciência, Tecnologia e Inovação, e de aceleradoras privadas destinam-se impulsionar esta economia no setor de 
tecnologia. Entretanto estas iniciativas não nos colocam numa posição confortável no cenário internacional e muito ainda precisa ser feito.

A criação e fomento aos projetos de incentivo às startups tem como principal finalidade desenvolver economicamente o país, assim como estimular o empreendedorismo, transformando o Brasil em um polo de inovação tecnológica. Dentre os programas desenvolvidos a fim de incentivar a criação e desenvolvimento destas empresas tecnológicas, este escrito irá dar ênfase aos benefícios fiscais, apresentados pela Lei de Inovação (Lei n. 10.973/2004, alterada pela Lei n. 13.243/2016), pela Lei do Bem (Lei n. 11.196/2005), pela Lei do Investidor Anjo (Lei Complementar n. 155/2016) e com a possibilidade de redução do ISS (Imposto Sobre Serviço) (FREITAS, 2017).

A Lei de Inovação (Lei n. 10.973/2004) trata de incentivos à inovação e à pesquisa científica e tecnológica no ambiente produtivo. Para uma maior efetividade desta lei, foi criada a Lei do Bem (Lei n. 11.196/2005), que, por sua vez, tem como finalidade viabilizar a concessão de incentivos fiscais às empresas que desempenham atividades de inovação tecnológica (BUFFON; JACOB, 2017). Nesse sentido, vide a ementa da Lei do Bem (Lei n. 11.196/2005):

Institui o Regime Especial de Tributação para a Plataforma de Exportação de Serviços de Tecnologia da Informação - REPES, o Regime Especial de Aquisição de Bens de Capital para EmpresasExportadoras - RECAP e o Programa de Inclusão Digital; dispõe sobre incentivos fiscais para a inovação tecnológica [...]. (BRASIL, 2005, online)

Um dos principais obstáculos enfrentados por esta lei é a falta de conhecimento sobre ela, sendo isso um fator de entrave à adesão deste benefício por diversas empresas, bem como a questão do lucro tributável, onde pessoas jurídicas com alto investimento em pesquisa, desenvolvimento e inovação tecnológica nem sempre apresentam um resultado fiscal positivo (COSTA, 2018). Uma mudança nesse panorama já seria possível com a simples ampliação da divulgação do referido dispositivo legal e suas respectivas vantagens às empresas que aderirem à Lei do Bem (Lei n. 11.196/2005).

A Lei do Investidor Anjo (Lei Complementar n. 155/2016) tem como finalidade incentivar o "investidor-anjo" a patrocinar microempresas e empresas de pequeno porte (regidas pela Lei Complementar n. 123/2006), fomentando, assim, a economia (POIDOMANI; OLIVEIRA FILHO, 2017). 
A figura deste investidor é de caráter transitório e não se submete aos riscos inerentes ao negócio, posto que não possui qualidade de sócio, não sendo parte do capital social. A lei ainda lhe concede benefícios como forma de incentivá-lo a investir em inovação tecnológica e naqueles empreendedores que não dispõem de recursos suficientes para promoverem o crescimento de sua própria empresa (POIDOMANI; OLIVEIRA FILHO, 2017).

Outra forma de incentivo às startups dá-se com a redução de alíquotas do Imposto Sobre Serviços (ISS). Todavia, cumpre ressaltar, que tal medida seria direcionada àquelas empresas prestadoras de serviços, bem como a variação da alíquota ficaria à margem de discricionariedade de cada Município, haja vista tratar-se de tributo de competência municipal, nos moldes do art. 156, III, da Constituição Federal. Ademais, insta salientar a necessidade da implantação de alíquotas similares, isto é, que cada Município, ao tratar do percentual aplicado sobre a base de cálculo para a quantificação do imposto, o faça de modo a levar em consideração a alíquota aplicada nas demais localidades.

\subsection{Políticas fiscais voltadas às startups}

A estipulação de tributos pelo Estado consiste numa ferramenta fundamental tanto para incentivar como para inibir determinados comportamentos. Segundo André Elali (2007, p. 41), a tributação surge para o ente estatal como instrumento de fomento ao desenvolvimento nacional, onde, por intermédio das normas tributárias, este poderá e deverá induzir os agentes econômicos a praticar determinados atos tidos como desejáveis na concretização da ordem econômica proposta pela Constituição Federal.

A concessão de incentivos e ou benefícios de natureza econômico-financeira é uma prática desempenhada pelo Brasil há décadas, com a finalidade de atrair investimentos, capital, promover o incremento das exportações, das pesquisas científicas, da indústria e do turismo. É certo que o exame da $\mathrm{CF} / 88$ revela que não há uma rígida padronização na própria terminologia adotada, e tampouco existe uma sistematização do assunto na Lex Magna.

Contudo, em apertada síntese, tem-se que aqueles tratamentos fiscais favorecidos podem ser percebidos sob a forma de imunidades e isenções tributárias, créditos presumidos, remissões, reduções na base de cálculo, regimes especiais etc. (ELALI, 2010).

Dentre as práticas desenvolvidas pelo país, pode-se citar a criação da Lei de Inovação (Lei n. 10.973/2004, alterada pela Lei n. 13.243/2016), atrelada à Lei do Bem (Lei 
n. 11.196/2005), que aplicadas em conjunto criam incentivos fiscais para empresas que investem em pesquisa e no desenvolvimento de novos produtos e processos voltados ao setor produtivo nacional (BUFFON; JACOB, 2017).

Cite-se, ainda, a anteriormente mencionada Lei do Investidor Anjo (Lei Complementar n. 155/2016) e a possibilidade de redução do Imposto Sobre Serviços - ISS, diplomas este que também possuem importante papel no cenário de incentivo e fomento à criação e desenvolvimento de startups.

Segundo André Elali (2010), as empresas brasileiras têm aumentado o seu grau de competitividade no âmbito internacional, por vezes induzidas por auxílios estatais, traduzidos na forma de incentivos tributários. Vê-se que a adoção de uma política tributária que preze pelo desenvolvimento industrial comparece como verdadeiro agente propulsor da economia. Para Aliomar Baleeiro (2015, p. 1374), “o período de maior crescimento da economia brasileira coincide com uma política intervencionista bastante expressiva e com a concessão de isenções, reduções de tributos etc., em volume elevado".

No atual cenário, onde há a criação e implantação de novas tecnologias no mercado, o Brasil deve exercer, de forma mais intensa, o papel de incentivador econômico-financeiro, a fim de atrair a atuação e incremento dessas empresas digitais denominadas startups. E isso pode ser implementado por meio de programas que assegurem um tratamento fiscal e/ou creditício que viabilize o desenvolvimento de projetos por parte das aduzidas empresas digitais.

De seu turno, a falta de avaliação mais detalhada sobre a criação de estímulos fiscais e seus efeitos multiplicadores tem deixado de atrair a atenção das autoridades fiscais (ANJOS DO BRASIL; GRANT THORNTON, 2017). Segundo estudo feito sobre o estímulo fiscal como ferramenta para o fomento do investimento em startups realizado pela organização sem fins lucrativos, Anjos do Brasil e a Grant Thornton Brasil (2017, p. 2):

Do ponto de vista econômico, o principal propósito da criação de um estímulo deve ser o de realocar recursos, isto é, alterar mediante incentivos o comportamento econômico dos agentes para alcançar um resultado melhor para a sociedade em comparação ao que aconteceria sem a sua utilização. Assim sendo, argumentos a favor da utilização de estímulos normalmente são baseados em conceitos de eficiência ou justiça social. Para ser efetivo, um incentivo deve atender ao objetivo de sua implementação com o custo mais baixo possível, em termos de carga fiscal ou redução da eficiência econômica. 
O Brasil, conforme visto, possui leis que podem viabilizar a criação e desenvolvimento de startups. Porém, a falta de conhecimento acerca do retorno econômico alcançado com tais práticas acaba por inviabilizar o fomento ao empreendedorismo tecnológico, de forma que os grandes investidores não se sentem atraídos economicamente ao papel de incentivador em virtude da concessão de poucos benefícios pelas autoridades fiscais.

O referido estudo, feito pelos Anjos do Brasil e pela Grant Thornton Brasil (2017, p. 8), concluiu que o investimento anjo tem capacidade de alavancar o PIB do país, sendo isso, para tanto, de suma relevância à economia moderna. Todavia, para que esta norma cumpra com sua finalidade, é preciso que ela garanta, de modo efetivo, estímulos maiores aos investidores, em virtude do alto risco assumido por tais empreendedores. Concluiu-se, ainda, que os incentivos de natureza fiscal, diferentemente do que acreditam as autoridades fiscais, não devem ser encarados exclusivamente como hipótese de renúncia tributária, porquanto muitos deles têm o condão de concorrer para o aumento da arrecadação (ANJOS DO BRASIL; GRANT THORNTON, 2017).

A Lei de Inovação, promulgada em 2004, foi alterada em determinados aspectos pela Lei n. 13.243/2016. Dentre as principais modificações, destacam-se as medidas de simplificação da relação entre as empresas e as instituições de pesquisa, bem como a possibilidade dos entes federativos de participarem do capital social. O principal objetivo destas alterações é fazer com que a legislação não seja mais um obstáculo às atividades de inovação tecnológica no país (SOLY, [2016?]).

Vê-se, portanto que a aludida Lei de Inovação (Lei n. 10.973/2004) contribui com a formação de um cenário propício ao desenvolvimento científico e tecnológico. O referido documento normativo encontra-se organizado em torno de três eixos:

1) Constituição de ambiente propício às parcerias estratégicas entre as universidades, institutos tecnológicos e empresas;

2) Estímulo à participação de instituições de ciência e tecnologia no processo de inovação;

3) Incentivo à inovação na empresa (PALMA, 2017, p. 48-49).

Aquele diploma legal (Lei n. 10.973/2004) possui uma melhor aplicação quando associada à Lei do Bem (Lei n. 11.196/05), que por sua vez traz em seu corpo diversos benefícios fiscais, tais como: dedução do Imposto de Renda e da Contribuição sobre o Lucro Líquido de gastos realizados com atividades de Pesquisa e Desenvolvimento, redução do 
Imposto sobre Produtos Industrializados - IPI quando da aquisição de máquinas e equipamentos, isenção do Imposto de Renda retido na fonte quando resultantes de remessas feitas ao exterior com a finalidade de registro e manutenção de marcas, patentes e cultivares (PALMA, 2017).

Por outro lado, apesar da criação de leis que concedam benefícios fiscais às inciativas tecnológicas, a cobrança de ISS (Imposto Sobre Serviços), sem atenção às especificidades das startups, é algo que onera e prejudica drasticamente a expansão deste tipo de negócio. Um exemplo disso são as empresas no formato $\mathrm{O}^{2} \mathrm{O}$ (modelo de negócio "online to offline"), que são aquelas que prestam serviço inicialmente em plataformas virtuais, mas que concretizam seus serviços em produtos físicos, tais como Ifood, EasyTaxi, Peixe Urbano etc. (RIBEIRO JUNIOR, 2016).

Essas startups que funcionam no formato "online to offline" realizam o recolhimento de ISS somente nos municípios em que possuem sede, de forma que seus parceiros, atuantes em outra localidade, pagam o imposto relativo àquela unidade federativa. $\mathrm{O}$ problema surge quando algumas cidades pretendem estabelecer um regime de recolhimento, a fim de tributar estas empresas nos mesmos moldes daquelas que prestam serviços unicamente no formato “offline” (RIBEIRO JUNIOR, 2016).

Com o intuito de pôr fim a essa "guerra fiscal” entre municípios, o Governo Federal sancionou a Lei Complementar n. 157/2016. Este veículo normativo assume um papel de possui suma importância para startups em virtude de alterar a Lei do ISSQN (Imposto Sobre Serviço de Qualquer Natureza), também conhecido como ISS (Imposto Sobre Serviços). Pela Lei Complementar n. 116/2003, cada Município cria uma lei ordinária para realizar a cobrança do respectivo tributo (CAVALCANTE, 2016).

A alteração principal, no que se refere às startups, diz respeito à criação de rol taxativo de serviços que estão sujeitos ao pagamento de ISSQN, deixando estas de ficarem à margem da discricionariedade dos Municípios que, por sua vez, acabavam taxando essas empresas de forma inapropriada, dificultando, assim, a sua manutenção (CAVALCANTE, 2016).

Em contrapartida, a Lei Complementar n. 157/2016 cuidou de vedar a concessão de isenções, incentivos ou benefícios fiscais, quando tal medida implique na incidência de alíquota inferior à mínima estabelecida pela referida norma (2\%), àquelas empresas que não 
se enquadrem nos itens 7.02, 7.05 e 16.01 da Lei Complementar n. 116/2003 (CAVALCANTE, 2016).

Verifica-se que por aquele comando legal as startups restariam prejudicadas, posto que estariam excluídas dos benefícios fiscais, das isenções ou dos incentivos quando tal concessão implicasse na incidência de alíquota inferior a $2 \%$.

Apesar da existência de legislação direcionada ao incentivo de criação e desenvolvimento das empresas de tecnologia, constata-se que, no âmbito tributário, ainda há muito a ser feito, pois de nada adiantaria a concessão de benefícios por parte das autoridades fiscais quando a própria prática econômico-tributária apresenta obstáculos à manutenção das startups.

\subsection{A relação das startups com o PIB}

O Produto Interno Bruto - PIB é um dos indicadores econômicos utilizados para se aferir o nível de desenvolvimento de um país. Todavia, nas considerações feitas por Amartya Sen (2010, p. 35), “o papel da renda e da riqueza - ainda que seja importantíssimo, juntamente com outras influências - tem de ser integrado a um quadro mais amplo e completo de êxito e privação.”.

Um PIB alto pode implicar o crescimento econômico, criação e expansão das empresas, levando a um aumento no número de empregos, bem como da competitividade no mercado exterior e redução da inflação. Sendo, em contrapartida, um entrave a este expansionismo uma complexa carga tributária, instabilidade política e procedimentos burocráticos que devem ser cumpridos pelas indústrias nas etapas de produção, contratação e venda de produtos (KUNAST, 2017).

Por outro lado, cumpre salientar que não pode persistir um "critério" único e preciso de desenvolvimento, segundo o qual as diversas experiências de desenvolvimento possam ser sempre comparadas e classificadas (SEN, 2010). Nesse sentido, o PIB não pode ser considerado como único indicador econômico de desenvolvimento nacional.

O impacto causado pelo crescimento econômico depende bastante da forma como seus frutos são utilizados. Isto é, não basta que um país demonstre ter um alto PIB para indicar uma boa economia, os frutos desta devem ser revertidos em proveito máximo à 
sociedade. Um mercado teria êxito, portanto, quando as oportunidades por ele oferecidas pudessem ser compartilhadas de forma razoável (SEN, 2010).

André Van Stel, Martin Carree e Roy Thurik (2005), ao tratar do efeito do empreendedorismo no crescimento econômico nacional, afirmam que a atividade empreendedora no seu estágio inicial é capaz de afetar a economia de um país, de modo que este efeito está condicionado àrenda per capita de cada região.

Apesar da variação de intensidade quanto à participação do empreendedorismo na economia nacional, verifica-se que este sempre se encontra presente quando o assunto em pauta é inovação, o que acaba servindo para ressaltar a importância da concessão de benefícios fiscais ao fomento desta atividade.

Segundo reportagem divulgada pelo Portal Contábil, as startups vêm avançando no Brasil, movimentando cerca de $\mathrm{R} \$ 2$ bilhões ao ano, representando 0,03\% do Produto Interno Bruto brasileiro. A meta de crescimento, estimada pela Associação Brasileira de Startups (ABStartups), é que estas empresas representem 5\% do PIB até 2035 (PORTAL CONTÁBIL SC, 2015).

Um fator de destaque das empresas é a sua versatilidade diante de cenários de crise. Tal característica se demonstra quando da ocorrência da recessão econômica havida no ano de 2016, onde muitos empreendimentos tradicionais passaram por graves dificuldades, enquanto que as startups conseguiram crescer (FONSECA, 2016).

A era dessas plataformas de tecnologia está apenas começando. Segundo o Correio Braziliense (EMPRESAS..., 2018), diversos setores estão sendo revolucionados, desde serviços de mobilidade urbana e segurança até serviços típicos de Estado que, por sua vez, são prestados pelo setor privado por meio de concessões, tais como educação e saúde, até mesmo os serviços financeiros estão sendo objeto de inovação.

O avanço das startups, conforme se tem percebido, possui um grande potencial para alavancar tanto o PIB nacional como para apresentar oportunidades criativas de desenvolvimento em momentos de crise econômica.

\section{O PAPEL DOS BENEFÍCIOS FISCAIS COMO INCENTIVADORES DO DESENVOLVIMENTO ECONÔMICO POR MEIO DA CRIAÇÃO DE STARTUPS}


Os benefícios ou incentivos fiscais também denominados "gastos tributários" se prestam à execução de políticas públicas e programas do governo, tendo como finalidade o desenvolvimento econômico ou social (EVANGELISTA et al, 2011). Todavia, como bem ressalta Carlos Renato Vieira do Nascimento (2013, p. 11), “os incentivos fiscais não podem servir como instrumento de um interesse político qualquer, mas apenas daqueles programas que estiverem formalmente e materialmente adequados aos princípios constitucionais.”.

Vê-se que a concessão de benefícios fiscais como fomento à criação e desenvolvimento de startups alinha-se ao interesse geral, qual seja, aumentar a arrecadação tributária, gerar empregos, renda e, consequentemente, ampliar o PIB nacional.

Por outro lado, é importante ressaltar que os benefícios tributários não podem implicar numa concessão desmedida de privilégios. É que, na essência, a própria natureza da tributação não deve admitir, ordinariamente, tratamento diferenciado entre os contribuintes que se encontrem em situações idênticas (prestadores de serviços, verbi gratia).

Diante disso, a extrafiscalidade, lídima forma de intervenção estatal na economia, pode ser tida como um parâmetro a guiar o legislador no concernente ao estabelecimento, se for o caso, de uma disciplina tributária favorecida a ser dispensada às startups.

Nesse sentido, Marciano Buffon e Lilian Ramos Jacob (2017, p. 124) afirmam que "as referidas desonerações deverão submeter-se a mecanismos, substancialmente democráticos de aprovação", ou seja, para cumprirem a finalidade a qual se propõem os benefícios fiscais devem propiciar o retorno financeiro esperado.

A própria Constituição Federal, em seu art. $218^{1}$, trata da instituição de mecanismos de incentivo a criação de novas tecnologias, sendo que, com a inserção dos artigos 219-A e 219-B pela Emenda Constituição no 85 de 2015, a atividade de fomento à tecnologia passou a contar com a parceria de entidades privadas. Deste modo, tanto o setor público como o privado atuam em prol do desenvolvimento da nação (BUFFON; JACOB, 2017).

O mercado das startups tem-se mostrado promissor. Segundo levantamento feito pela Associação Brasileira de Startups, estima-se que existem dez mil negócios desse tipo no Brasil e que em 2012 chegaram a movimentar cerca de $\mathrm{R} \$ 2$ bilhões de reais (INSTITUTO MILLENIUM, 2014).

\footnotetext{
1 “Art. 218, CF/88, O Estado promoverá e incentivará o desenvolvimento científico, a pesquisa, a capacitação científica e tecnológica e a inovação.” (BRASIL, 1988, online).
} 
Em entrevista concedida ao Instituto Millenium (2014, online), Abaetê de Azevedo (presidente da DiversifiedAgency Services - DAS da Omnicom, maior conglomerado mundial de comunicação), afirma, quando questionado sobre o impacto das startups na economia brasileira:

Do ponto de vista do volume de dinheiro produzido, o impacto ainda é pequeno. Agora, se falarmos de impacto social, estamos no início do que virá a ser uma imensa onda de novos empregos. Não vamos ter um ambiente povoado apenas por poucas e grandes empresas. $\mathrm{O}$ ambiente empresarial começa a ser povoado de pequenas e médias empresas, gerando mais empregos e diversificando a economia. Como são empresas baby, as startups produzem pouco dinheiro, mas elas têm um impacto social enorme porque modernizam e ampliam o raciocínio estratégico de negócios do país. Maneiras novas de pensar oxigenam a economia.

Apesar de terem um impacto econômico pouco expressivo nesse primeiro momento, cumpre ressaltar que a expectativa é de ativos positivos, conforme demonstra levantamento feito pela Associação Brasileira de Startups (PORTAL CONTÁBIL SC, 2015).

O fomento público às inciativas tecnológicas se mostra como uma peça fundamental a esse avanço em virtude de que uma das principais dificuldades enfrentadas pelas pequenas e médias empresas é o Custo Brasil, traduzido pelo excesso de burocracias e impostos (INSTITUTO MILLENIUM, 2014). Para Abaetê (2014, online), essas empresas “já nascem com a sua lucratividade comprometida em função do ambiente hostil à iniciativa privada.”.

Como visto no tópico 3.1 deste trabalho, apesar da existência de legislação direcionada à criação e ao fomento das empresas de tecnologia, é necessária uma mudança de postura no que diz respeito à prática econômico-tributária. A instituição dos tributos deve se coadunar com as normas instituídas, viabilizando, assim, o desenvolvimento das startups.

\section{CONCLUSÃO}

O empreendedorismo é algo que não pode ser desvencilhado da economia, principalmente no atual cenário em que se encontra o Brasil, buscando alcançar a nova revolução industrial, também conhecida como Indústria 4.0. 
Conforme visto, o âmbito legislativo dispõe de normas que tratam de benefícios fiscais quando do patrocínio para criação e manutenção das startups, todavia, para que tais leis sejam capazes de propiciar um terreno fértil ao desenvolvimento econômico, é necessário expandir os incentivos concedidos aos investidores anjo (figura da Lei Complementar n. 155/2016).

As startups estão mostrando-se como um importante vetor de crescimento econômico, oportunidade que propiciam um aumento na arrecadação tributária e na criação de empregos. Outrossim destacam-se, ainda, pela sua estabilidade em época de crise, uma vez que se tratam de empresas versáteis.

Essas empresas tecnológicas têm deparado-se com obstáculos tanto no que diz respeito à sua criação quanto ao seu desenvolvimento. Um fator que foi apresentado no presente trabalho diz respeito às dificuldades destas em lidar com o Imposto Sobre Serviços, em virtude do tratamento dado por cada Município que, por sua vez, quer considerá-las como empresas "offline", tributando, assim, toda e qualquer atividade desenvolvida no território municipal.

Viu-se que a criação da Lei Complementar n. 157/2016 solucionou alguns problemas enfrentados pelas startups ao criar um rol taxativo para determinar a incidência do tributo (ISS). Mas, em contrapartida, inviabilizou a concessão de benefícios fiscais ao limitá-los ao percentual de até $2 \%$ da alíquota mínima a ser praticada, via de regra, por todos os Municípios.

Depreende-se, portanto, que apesar da existência de legislação direcionada ao incentivo de criação e desenvolvimento das empresas de tecnologia, no âmbito tributário, ainda há muito a ser feito, pois de nada adiantaria a concessão de benefícios por parte das autoridades fiscais quando a própria prática econômico-tributária apresenta obstáculos à manutenção das startups.

Um Estado que, além de não incentivar a inserção de novos mercados no território nacional, obstacula a atuação destes com severas práticas tributárias não se mostra em consonância com o desenvolvimento proposto pela nova revolução industrial.

\section{REFERENCIAS}

ALVES, Fábia Santos. Um estudo das startups no Brasil. 2013. 76 p. Monografia (Bacharelado em Ciências Econômicas). Faculdade de Economia da Universidade Federal da 
Bahia, Salvador, 2013. Disponível em: <https://repositorio.ufba.br/ri/handle/ri/15395>. Acesso em: 5 jun. 2018.

ANJOS DO BRASIL; GRANT THORNTON. O estímulo como ferramenta para o fomento do investimento em startups: o caso do investidor anjo. Disponível em: $<$ http://www.anjosdobrasil.net/uploads/7/9/5/6/7956863/estudo_sobre_estimulo_para_investi mento_em_startups_-_anjos_do_brasil_e_grant_thornton.pdf $>$. Acesso em: 19 jul. 2018.

ARRUDA, José Jobson de A. História Moderna e Contemporânea. 14 ed. São Paulo: Ática, 1982.

ASSOCIAÇÃO BRASILEIRA DAS EMPRESAS DE TECNOLOGIA DA INFORMAÇÃO E COMUNICAÇÃO. Relatório: Startups. São Paulo, 2017. Disponível em: < http://www.brasilitplus.com/brasilit/upload/download/1416332923startups.pdf>. Acesso em 2 jun. 2018.

BALEEIRO, Aliomar. Direito Tributário Brasileiro. Atualizada por Misabel Abreu Machado Derzi. 13 ed. Rio de Janeiro: Forense, 2015.

BRASIL. Agenda brasileira para a Indústria 4.0: o Brasil preparado para desafios do futuro, [online], 2017. Disponível em: <http://www.industria40.gov.br/>. Acesso em 4 jun. 2018.

BRASIL. Constituição (1988) Constituição da República Federativa do Brasil. Texto constitucional promulgado em 5 de outubro de 1988. Brasília, DF, Senado, 1998. Disponível em: < http://www.planalto.gov.br/ccivil_03/constituicao/constituicaocompilado.htm>. Acesso em: 10 abr. 2018.

BRASIL. Lei n. 11.196, de 21 de novembro de 2005. Institui o Regime Especial de Tributação para a Plataforma de Exportação de Serviços de Tecnologia da Informação REPES, o Regime Especial de Aquisição de Bens de Capital para Empresas Exportadoras RECAP e o Programa de Inclusão Digital; dispõe sobre incentivos fiscais para a inovação tecnológica; e dá outras providências. Diário Oficial [da] República Federativa do Brasil, Brasília, DF, 21 nov. 2005. Disponível em: <http://www.planalto.gov.br/ccivil_03/_ato20042006/2005/lei/111196.htm>. Acesso em: 10 jul. 2018.

BUFFON, Marciano; JACOB, Lilian Ramos. Os incentivos fiscais no ramo tecnológico como instrumento do desenvolvimento nacional. Direito e desenvolvimento, João Pessoa, v. 6, n. 2, p. 121-144, jun. 2017. Disponível em: <https://periodicos.unipe.br/index.php/direitoedesenvolvimento/article/view/292>. Acesso em: 10 jun. 2018.

CAVALCANTE, Márcio André Lopes. LC 157/2016 promove alterações na Lei do ISS (LC 116/2003). Dizer o Direito [site], 30 dez. 2016. Disponível em:

<https://www.dizerodireito.com.br/2016/12/lc-1572016-promove-alteracoes-na-lei-do.html>. Acesso em: 21 jul. 2018. 
COSTA, Rafael. Startups e a Lei do Bem. Disponível em:

$<$ http://www.portaltributario.com.br/artigos/startups-e-a-lei-do-bem.htm>. Acesso em: 10 jul. 2018.

ELALI, André. "Incentivos fiscais, neutralidade da tributação e desenvolvimento econômico: a questão da redução das desigualdades regionais e sociais." In: MARTINS, Ives Gandra da Silva; ELALI, André; PEIXOTO, Marcelo Magalhães. Incentivos fiscais: questões pontuais nas esferas federal, estadual e municipal. São Paulo: MP Editora, 2007.

ELALI, André. Incentivos fiscais internacionais: concorrência fiscal, mobilidade financeira e crise do Estado. São Paulo: QuartierLatin, 2010.

EMPRESA BRASILEIRA DE INOVAÇÃO E PESQUISA. Finep Startup. Disponível em: <http://www.finep.gov.br/apoio-e-financiamento-externa/programas-e-linhas/finep-startup > Acesso em: 10 jul. 2018.

EMPRESAS de base tecnológica, startups avançam a passos largos no Brasil. Correio Braziliense, Brasília, 11 fev. 2018. Disponível em: < https://www.correiobraziliense.com.br/app/noticia/economia/2018/02/11/internas_economia,6 59174/empresas-de-base-tecnologica-startups-avancam-a-passos-largos-no-bras.shtml>. Acesso em: 10 jun. 2018.

EVANGELISTA, Charles Mathusalém Soares et al. Perspectivas do controle sobre benefícios fiscais: avaliação da Política Nacional de Desenvolvimento Regional (PNDR). Revista do TCU, online, p. 46-61, maio/ago. 2011. Disponível em: < revista.tcu.gov.br/ojs/index.php/RTCU/article/view/180/175>. Acesso em: 21 jul. 2018.

FIRJAN. Panorama da inovação: Indústria 4.0. Disponível em:

<http://www.firjan.com.br/publicacoes/publicacoes-de-inovacao/industria-4-0-1.htm>. Acesso em: 5 jun. 2018.

FONSECA, Mariana. 13 startups brasileiras que fizeram a diferença em 2016. Exame, São Paulo, 28 dez. 2016. Disponível em: <https://exame.abril.com.br/pme/13-startups-brasileirasque-fizeram-a-diferenca-em-2016/>. Acesso em: 11 jun. 2018.

FREITAS, Cristiano. 5 benefícios fiscais para startups que você não conhecia. Disponível em: <http://syhus.com.br/2017/08/31/5-beneficios-fiscais-para-startups-que-voce-naoconhecia/>. Acesso em: 10 jul. 2018.

INSTITUTO MILLENIUM. "As startups têm um impacto social enorme". Disponível em: $<$ https://www.institutomillenium.org.br/divulgacao/entrevistas/startups-tm-um-impactosocial-enorme/>. Acesso em: 21 jul. 2018.

KÜNAST, Luana. O que é e como funciona o PIB? Disponível em: < https://www.estudopratico.com.br/o-que-e-e-como-funciona-o-pib/>. Acesso em: 10 jun. 2018. 
MACEDO, Neusa Dias de. Iniciação a pesquisa bibliográfica: guia do estudante para a fundamentação do trabalho de pesquisa. 3. ed. São Paulo: Edições Loyola, 1995.

MOREIRA, Daniela. O que é uma startup? Exame, São Paulo, 3 fev. 2016. Disponível em: $<$ https://exame.abril.com.br/pme/o-que-e-uma-startup/>. Acesso em: 5 jun. 2018.

NASCIMENTO, Carlos Renato Vieira do. Políticas Públicas e Incentivos Fiscais. Revista de Finanças Públicas Tributação e Desenvolvimento, Rio de Janeiro, v. 1, n. 1, p. 1-18, 2013. Disponível em: <http://www.e-publicacoes.uerj.br/index.php/rfptd/article/view/5125>. Acesso em: 20 jul. 2018.

PALMA, André Luiz Bortolato da. Ambientes e incentivos fiscais para inovação: uma proposta para criação do Núcleo do Parque Ecológico da Universidade de São Paulo. 2017. 121 f. Dissertação (Mestrado em Empreendedorismo). Universidade de São Paulo, São Paulo, 2017. Disponível em: < http://www.teses.usp.br/teses/disponiveis/12/12142/tde-15032018152056/pt-br.php>. Acesso em: 21 jul. 2018.

POIDOMANI, Isabella Lucia; OLIVEIRA FILHO, João Glicério de. Análise crítica da Lei Complementar $n^{\circ} 155$ de 2016 na regulamentação do investidor-anjo. Revista Brasileira de Direito Empresarial, Maranhão, v. 3, n. 2, p. 22-39, jul./dez. 2017. Disponível em: <http://indexlaw.org/index.php/direitoempresarial/article/view/2337>. Acesso em: 10 jul. 2018 .

PORTAL CONTÁBIL SC [site]. Startups crescem $18 \%$ no País e giram R\$ 2 bilhões anualmente na economia. Florianópolis, SC: Economia Notícias, 2015. Disponível em: < http://portalcontabilsc.com.br/noticias/startups-crescem-18-no-pais-e-giram-r-2-bilhoesanualmente-na-economia/>. Acesso em: 10 jun. 2018.

RIBEIRO JUNIOR, Valdir. Confusão com tributo pode atrapalhar expansão de startups, diz entidade. Revista Pequenas Empresas \& Grandes Negócios [online], 29 mar. 2016. Disponível em: <https://revistapegn.globo.com/Dia-a-dia/noticia/2016/03/confusao-comtributo-pode-atrapalhar-expansao-de-startups-diz-entidade.html>. Acesso em: 21 jul. 2018.

ROMANO, Matheus. Entenda o que é IoT na Indústria 4.0 e porque isso é uma aposta que vai revolucionar o mercado industrial, [online], 2017. Disponível em: < http://www.logiquesistemas.com.br/blog/iot-na-industria-4-0/>. Acesso em: 6 jun. 2018.

SEBRAE. O que é uma startup? Disponível em: < http://www.sebrae.com.br/sites/PortalSebrae/sebraeaz/o-que-e-umastartup,616913074c0a3410VgnVCM1000003b74010aRCRD>. Acesso em: 4 jun. 2018.

SEN, Amartya. Desenvolvimento como liberdade. Tradução de Laura Teixeira Motta. São Paulo: Companhia das Letras, 2010.

SCHWAB, Klaus. A quarta revolução industrial. Tradução de Daniel Moreira Miranda. São Paulo: Edipro, 2016. 
SOLY, Bruna. Lei de Inovação: instrumentos de estímulo à inovação nas empresas.

Disponível em: <http://brasil.abgi-group.com/radar-inovacao/artigos-estudos/lei-de-inovacaoinstrumentos-de-estimulo-a-inovacao-nas-empresas/>. Acesso em: 21 jul. 2018.

STEL, André Van; CARREE, Martin; THURIK, Roy.The Effect of EntrepreneurialActivityon NationalEconomic Growth. Small Business Economics [online], v. 24, n. 3, p. 311-321, apr. 2005. Disponívelem: <https://link-springercom.ez11.periodicos.capes.gov.br/article/10.1007/s11187-005-1996-6>. Acesso em: 20 jul. 2017. 